Z. klin. Chem. u. klin. Biochem.

8. Jg., S. 570-571, November 1970

\title{
Disaccharidasenaktivität und Monosaccharidabsorption bei genetisch adipösen Mäusen')
}

\author{
Von K. Grimmel, L. Rakow, K. Rommel, K. Lacher und F. Burkhardt
}

\begin{abstract}
Aus der Sektion für Klinische Chemie (Leiter: Doz. Dr. K. Rom mel) des Zentrums für Innere Medizin und Kinderbeilkunde und der Abteilung für Patbologie II (Leiter: Prof. Dr. G. Beneke) des Zentrums für Biologie und Theoretische Medizin der Universität Ulm
\end{abstract}

(Eingegangen am 16. Juni 1970)

Bei genetisch adipösen Mäusen und ihren normalgewichtigen Geschwistern wurden die Galaktoseabsorption in vitro und die Disaccharidasen-Aktivität des Dünndarms untersucht. Während zwischen beiden Gruppen keine Unterschiede in der Galaktose-Absorption bestanden, waren die Disaccharidasen Maltase, Isomaltase und Saccharase bei genetisch adipösen Mäusen signifikant erhöht.

\section{Disaccharidase activity and monosaccharide absorption in genetically adipose mice}

The absorption of galactose in vitro and the disaccharidase activity of the small intestine were measured in genetically adipose mice and in their siblings of normal weight. There were no diffcrences in galactose absorption between the two groups, but maltase, isomaltase and sucrase were significantly higher in the genetically adipose mice.

1949 trat im Jackson Memorial Laboratory in Bar Harbor/USA spontan eine autosomal rezessiv sich vererbende Mutante der Hausmaus auf, die sich durch eine Hyperglykämie und durch eine im Alter von 4-6 Wochen bereits exkennbare, stetig zunehmende Fettsucht auszeichnete (1). Die seither aufgedeckten Stoffwechselabweichungen dieser genetisch adipösen, hyperglykämischen Mäuse sind von MAYer $(2,3)$ zusammengestellt worden. Als Teilursache für die Progredienz der Adipositas wird die Inaktivität der Tiere angeschuldigt (4). Es ist außerdem über eine gesteigerte GlucoseAbsorption berichtet worden (5).

In der vorliegenden Arbeit werden die beiden wichtigsten Schritte der Kohlenhydrataufnahme vom Darm in das Blut - die Spaltung der Disaccharide und die Monosaccharidabsorption - durch Bestimmung der Disaccharidasenaktivität und der Galaktoseabsorption bei genetisch adipösen Mäusen untersucht.

\section{Material und Methodik}

Die Untersuchungen wurden an 6 genetisch adipösen und 6 Kontrollmäusen beiderlei Geschlechts (Bar-Harbor-Stamm C 75 BLob) durchgeführt. Zuchttiere dieses Stammes erhielten wir vom Jackson Memorial Laboratory in Bar Harbor/USA. Die Mäuse wurden in der Zentralen Versuchstieranlage der Universität Ulm (Leiter: Dr. med. vet. H. P. Schnappauf) weitergezüchtet. Die Versuchstiere waren 5-6 Monate alt. Die homozygoten obesen Tiere hatten ein mittleres Gewicht von 53,3 g, die normalgewichtigen Kontrollen wogen im Mittel 22,3 g. Die Ernährung erfolgte mit dem Standardfutter Altromin $1115 \mathrm{R}$ (Altromin GmbH, Lage/Lippe) und Wasser ad libitum. In den letzten 24 Stdn. vor der Tötung erhielten die Mäuse jedoch nur ungesalzenen Schweinespeck als Futter. Nach dem Töten der Tiere durch Ausbluten im Ätherrausch wurde der Dünndarm entnommen. Am oralen Ende beginnend wurden sofort jeweils 7, im Mittel 39,4 mg schwere Dünndarmstückchen abgeschnitten und in Krebs-Ringer-Puffer $(\mathrm{pH} 7,2, \mathrm{Car}$ 1) Mit Unterstützung der Deutschen Forschungsgemeinschaft,
Bad Godesberg.
bogen-Begasung), der pro $100 \mathrm{~m} / 1 \mathrm{~g}$ Galaktose enthielt, bei $37^{\circ}$ inkubiert. Nach 0, 1, 3, 5, 10, 20 und 30 Min. wurde je ein Darmstückchen entnommen, in Ringer-Lösung gespült, mit einem Potter-Elvehjem-Homogenisator in $1 \mathrm{~m} l$ eisgekühlter $0,6 \mathrm{M}$ Perchlorsäure homogenisiert und anschließend im Uberstand die Galaktose, bezogen auf ng DNA, nach der Methode von RommeL und Mitarbeitern (6) gemessen.

In einem sich an die zur Inkubation entnommenen Proben anschlieBenden Dünndarmstückchen wurde die Aktivität der Maltase, Isomaltase, Lactase, Palatinase und Saccharase, bezogen auf ng DNA, in Anlehnung an die Methode von HANSEN und Mitarbeitern (7) bestimmt.

Der DNA-Gehalt eines jeden entnommenen Dünndarmstückchens wurde nach Burton (8), der RNA-Gehalt nach Cerrottr (9) bestimmt.

Die Signifikanzprüfung erfolgte mit Hilfe des t-Testes für unverbundene Stichproben.

\section{Ėrgebnisse}

Tabelle 1 und Abbildung 1 zeigen, daß die Galaktoseaufnahme pro ng DNA der genetisch adipösen Tiere sich nicht von der der Kontrollen unterscheidet; $p$ ist für alle Inkubationszeiten $>0,30$. Nach einem raschen nicht-linearen Anstieg der Galaktoseaufnahme in den ersten $5 \mathrm{Min}$. kommt es dann zu einer linearen Zunahme des Galaktose-Uptake.

Die Disaccharidasen-Aktivitäten pro ng DNA sind in Tabelle 2 und Abbildung 2 zusammengestellt. Bei den Kontrolltieren verhalten sich die Disaccharidasen Maltase : Isomaltase : Saccharase : Palatinase : Lactase wie 21:16:3:1:1 und bei den adipösen Mäusen wie $46: 35: 11: 2: 1$. Signifikant erhöht sind bei den genetisch adipösen Mäusen die Aktivität der Maltase, der Isomaltase und der Saccharase, während die - insgesamt sehr geringe - Aktivität der Lactase und der Palatinase sich nicht signifikant von der der Kontrolltiere unterscheidet.

Der auf $100 \mathrm{mg}$ Feuchtgewicht bezogene DNA-Gehalt des Dünndarms genetisch adipöser Mäuse zeigt keine 
Tab. 1

Mittlere Galaktoseaufnahme des Dünndarms genetisch adipöser Mäuse und eines normalgewichtigen Kontroll-Kollektivs in vitro

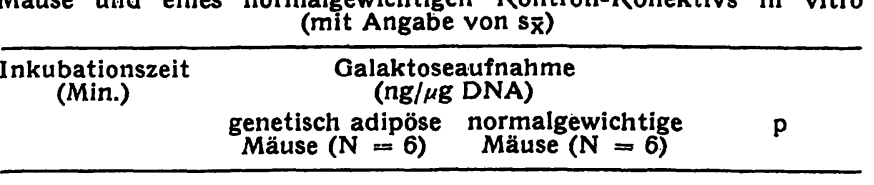

\begin{tabular}{rrrl}
\hline 0 & $0 \pm 0$ & $0 \pm 0$ & \\
1 & $115 \pm 33$ & $100 \pm 22$ & $>0,35$ \\
3 & $132 \pm 14$ & $161 \pm 54$ & $>0,30$ \\
5 & $172 \pm 67$ & $177 \pm 48$ & $>0,475$ \\
10 & $268 \pm 59$ & $234 \pm 41$ & $>0,30$ \\
20 & $270 \pm 89$ & $255 \pm 68$ & $>0,45$ \\
30 & $348 \pm 48$ & $325 \pm 72$ & $>0,35$ \\
\hline
\end{tabular}

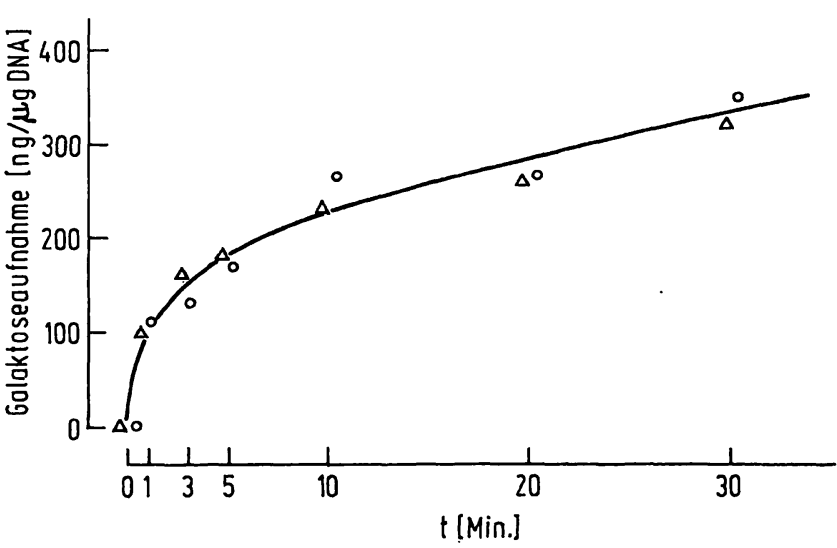

Abb. 1

Mittlere Galaktoseaufnahme des Dünndarms genetisch adipöser Mäuse (o) und normalgewichtiger Geschwistertiere $(\Delta)$ in vitro

signifikanten Unterschiede zu dem normalgewichtiger Geschwistertiere $(0,92 \pm 0,33 \mathrm{mg}$ bei genetisch adipösen, 0,95 $\pm 0,27 \mathrm{mg}$ bei normalgewichtigen Mäusen; $\mathrm{p}>0,30)$. Auch der RNA/DNA-Quotient ist bei beiden Kollektiven nicht signifikant verschieden $(1,07 \pm 0,28$ bei genetisch adipösen, $1,12 \pm 0,51$ bei normalgewichtigen Tieren; $p>0,40$ ).

\section{Diskussion}

Mayer und Yannoni (5) haben bei Glucose-Absorptions-Studien in vivo an genetisch adipösen Mäusen gegenüber normalgewichtigen Kontrolltieren eine gesteigerte Glucose-Aufnahme bei unverändertem Darmgewicht und keinem Unterschied in der Magenentleerung gefunden. Wir konnten die gesteigerte $\mathrm{Ab}$ sorption in vitro mit Galaktose nicht bestätigen. Die von MaYer und YanNonI (5) benutzten Glucose-Konzentrationen waren um den Faktor 10 bis 80 höher als die von uns benutzte Galaktose-Konzentration von $1 \mathrm{~g} /$ $100 \mathrm{ml}$; vielleicht liegt hierin eine Teilerklärung der unterschiedlichen Ergebnisse. Darüber hinaus ist ein
Tab. 2

Vergleich der mittleren Disaccharidase-Akticität des Dünndarms genetisch adipöser und normalgewichtiger Mäuse mit Angabe der
Standardabweichung $S(N=6)$

\begin{tabular}{|c|c|c|c|}
\hline \multirow[t]{2}{*}{ Disaccharidasen } & \multicolumn{2}{|c|}{$\begin{array}{c}\text { Disaccharidasenaktivität } \\
\text { (U/ng DNA) }\end{array}$} & \multirow[b]{2}{*}{$\mathrm{p}$} \\
\hline & $\begin{array}{c}\text { genetisch adipöse } \\
\text { Mäuse }\end{array}$ & $\begin{array}{c}\text { normalgewichtige } \\
\text { Mäuse }\end{array}$ & \\
\hline Maltase & $2,95 \pm 1,39$ & $1,71 \pm 0,92$ & $<0,05$ \\
\hline Isomaltase & $2,27 \pm 0,90$ & $1,30 \pm 0,66$ & $<0,05$ \\
\hline Saccharase & $0,68 \pm 0,24$ & $0,23 \pm 0,15$ & $<0,0025$ \\
\hline Palatinase & $0,15 \pm 0,14$. & $0,09 \pm 0,08$ & $>0,020$ \\
\hline Lactase & $0,06 \pm 0,04$ & $0,08 \pm 0,07$ & $>0,30$ \\
\hline
\end{tabular}

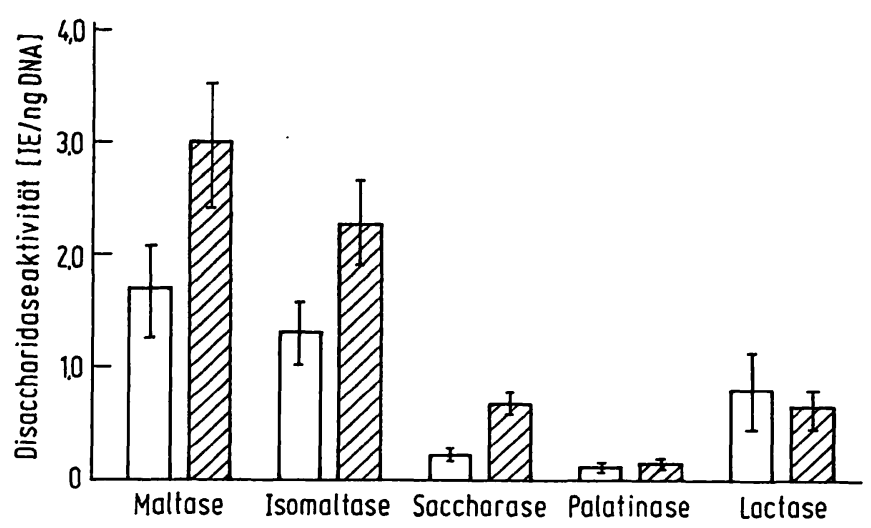

Abb. 2

Mittlere Aktivität intestinaler Disaccharidasen bei normalgewichtigen (offene Säulen) und genetisch adipösen (schraffiert) Mäusen (mit Angabe von $s_{\bar{x}}$ )

Vergleich von in vitro- und in vivo-Befunden, vor allem wegen der hormonellen und der zirkulatorischen $\mathrm{Be}-$ einflussung der Absorption, prinzipiell problematisch. Nach unseren Ergebnissen unterscheiden sich jedenfalls genetisch adipöse Mäuse nicht von ihren normalgewichtigen Geschwistern hinsichtlich des Grundvorgangs der Adsorption eines aktiv absorbierten Monosaccharids.

Anders verhalten sich die Disaccharidasen. Ihre Aktivität ist in unterschiedlichem Ausmaß bei den adipösen Mäusen vermehrt, so daß es auch zu einer Verschiebung der Relation der einzelnen. Aktivitäten zueinander kommt. Nur das Verhältnis Maltase/Isomaltase bleibt gleich. Da nach Untersuchungen von CRANE und seiner Arbeitsgruppe (10) Mono- und Disaccharide offenbar über zwei verschiedene Carrier transportiert werden, kann die erhöhte Disaccharidasen-Aktivität genetisch adipöser Mäuse bei gleichem Kohlehydratangebot im Futter doch zu einer vermehrten Zuckeraufnahme vom Darm ins Blut führen, obwohl die primäre Monosaccharid-Absorption nicht gesteigert ist.

\section{Literatur}

1. Ingalls, A. M., M. M. Dickie und G. D. SNetr, J. Hered. 41, 317 (1950). - 2. MAYER, J., Am. J. Clin. Nutr. 8, 712 (1960). 3. Mayer, J., Ann. Rev. Med. 14, 111 (1963). - 4. Mayer, J., N. B. Marshald, J. J. Vitale, J. H. Christensen, M. B. MashaYekhi und F. J. Stare, Amer. J. Physiol. 177, 544 (1965). - 5. Mayer, J., und C. Z. YannonI, Amer. J. Physiol. 185, 49 (1956). 6. Rommel, K., E. Bernt, F. Schmitz und K. Grimmel, Klin.
Wschr. 46, 936 (1968). - 7. Hansen, H. Tir., H. Chr. Drube, U. E. KLEIN und K. Z IELKE, Gastroenterologia 106, 345 (1966). 8. Burton, K., Biochem. J. 62, 315 (1959). - 9. Ceriotri, G., J. biol. Chemistry 214, 59 (1956). - 10. Crane, R. K., in: Rommer, Clodr (Hrsg.): Conference on biochemical and clinical aspects of sugar absorption. Titisec 1969 (in Vorbereitung). 